\title{
Gastric Intestinal Metaplasia Is the Most Common Histopathological Phenotype among Endoscopically Diagnosed Atrophic Gastritis Patients in North-East China
}

\author{
Tayyab Hamid Malik¹, Caihan Zhao', Jafer Mohammed AlAhmed², Sohaib Ahmad Alam², \\ Hong $\mathrm{Xu}^{1^{*}}$ \\ ${ }^{1}$ Department of Gastroenterology and Endoscopy Center, First Hospital of Jilin University, Jilin, China \\ ${ }^{2}$ Norman Bethune Health Science Center, Jilin University, Jilin, China \\ Email: emailtayyab@yahoo.com, *chxuhong@163.com
}

How to cite this paper: Malik, T.H., Zhao, C.H., AlAhmed, J.M., Alam, S.A. and Xu, H. (2017) Gastric Intestinal Metaplasia Is the Most Common Histopathological Phenotype among Endoscopically Diagnosed Atrophic Gastritis Patients in North-East China. Open Journal of Gastroenterology, 7, 65-74.

https://doi.org/10.4236/ojgas.2017.72008

Received: January 9, 2017

Accepted: February 12, 2017

Published: February 15, 2017

Copyright $\odot 2017$ by authors and Scientific Research Publishing Inc. This work is licensed under the Creative Commons Attribution International License (CC BY 4.0).

http://creativecommons.org/licenses/by/4.0/

\begin{abstract}
Background: Gastric cancer and gastric precancerous lesions are highly prevalent in China. However, prevalence of the different precancerous lesions has not been reported from the north-east region of China. Detection of precancerous gastric lesions at an early stage complemented with a follow-up strategy for high risk groups would probably aid in declining the mortality rate in patients with gastric cancer. Helicobacter pylori infection, salt intake, smoking, alcohol, family history of gastric cancer, atrophic gastritis and intestinal metaplasia are established risk factors of gastric cancer. The aim of this study was to evaluate the frequency of various histopathological phenotypes among atrophic gastritis patients in this region and to report if gender and increasing age carry risk in the development of these lesions. Methods: This retrospective study was conducted on 518 patients with endoscopic diagnosis of atrophic gastritis. Using the patient number in database, histopathological diagnosis of the biopsy specimen of all patients was recorded. All biopsy specimens were assessed for the presence of inflammation, atrophic gastritis, metaplasia and/or dysplasia. Results: Intestinal metaplasia was observed in $67.38 \%$ of patients. Dysplasia and atrophy were present in $9.46 \%$ and $3.67 \%$ patients, respectively. Gender and increasing age were not found to be risk factors for intestinal metaplasia, dysplasia and atrophic gastritis (p-values $0.08,0.43,0.297$ and $0.98,0.20,0.54$; respectively). $19.49 \%$ subjects showed inflammatory activity which was significantly associated with female gender $(\mathrm{P}=0.0008)$. Conclusion: Intestinal metaplasia was the most histopathological phenotype among endoscopically diagnosed atrophic gastritis patients. Large-population based on prospective studies should be designed to determine prevalence of precancerous lesions and the risk factors involved in
\end{abstract}


the progression of these lesions in our region.

\section{Keywords}

Atrophic Gastritis, Endoscopy, Metaplasia, Gastric Cancer

\section{Introduction}

Gastric cancer (GC) is the fourth most common cancer worldwide [1] while it ranks the third most common cancer in China [2]. GC remains the second leading cause of cancer-related death around the globe [3], despite tremendous advancement in diagnostic and therapeutic endoscopy techniques. Detection of precancerous gastric lesions at an early stage complemented with a follow-up strategy for high risk groups would probably aid in declining the mortality rate in GC patients. Helicobacter pylori (H. pylori) infection, salt intake, smoking, alcohol, family history of gastric cancer, atrophic gastritis (AG) and intestinal metaplasia (IM) are established risk factors of gastric cancer [4].

Atrophic gastritis, defined as the loss of glands [5] is well known as a risk factor of gastric cancer. Endoscopic AG is characterized by the loss of gastric mucosal gland and submucosal vascular pattern visibility. AG is usually diagnosed at endoscopy in Asian countries-in particular-East Asian countries while histological examination of biopsy obtained during endoscopy is a necessity for AG diagnosis in the western countries. Marques-Silva et al. [6] carried out a metanalysis to study the distribution of precancerous gastric lesions around the globe. The prevalence of atrophic gastritis and IM in the worldwide population was $33.4 \%$ and $25 \%$ respectively, whereas extensive IM was found in $13 \%$. They further found that precancerous lesions-AG and IM-were more prevalent in countries with high incidence of gastric cancer. Chronic atrophic gastritis is highly prevalent in China [7] and has a 5-fold tendency to progress to malignancy [8].

To the best of our knowledge, this is the first study from North-East region of China to document the frequency of various precancerous lesions in atrophic gastritis patients. We also evaluated if gender and increasing age are associated with the development of gastric precancerous lesions.

\section{Methods}

This retrospective study was conducted on 518 patients with endoscopic diagnosis of AG, from January 2012 to November 2014, at the Department of Gastroenterology and Endoscopy Center, First Hospital of Jilin University, Changchun, China. Demographic data of inducted patients was retrieved by observing the patients electronic record in the database. Patients whose presenting history revealed active GI bleeding and/or use of proton pump inhibitor/H2 receptor antagonist were not inducted in the study. The Ethics Committee of our hospital approved the study. 
One biopsy was taken from the corpus while two biopsies were taken from antrum of all study subjects. Biopsy specimens were placed in vials containing $10 \%$ buffered formalin solution. Slides were stained with hematoxylin and eosin. Biopsy specimens were examined by senior pathologist specialized in gastric mucosal abnormalities. All specimens were assessed for the presence of inflammation, atrophic gastritis, metaplasia and/or dysplasia.

\section{Statistical Analysis}

Descriptive statistics for continuous variables (characteristics) were presented as mean, standard deviation, and minimum and maximum values. Multivariate logistic regression was used to determine association of risk factors (gender and increasing age) with the precancerous lesions. Odds ratios (OR) and 95\% confidence intervals (CI) were calculated. In addition, Fisher's exact test was performed to compare two proportions in groups. A P value of less than 0.05 was considered to be statistically significant.

\section{Results}

\subsection{Basic Characteristics of Patients and Pathology Findings}

518 patients (196 females and 322 males) were diagnosed with atrophic gastritis at endoscopy. Age ranged from 18 to 90 years while mean age was 60.54 years $( \pm 10.97 \mathrm{SD})$. After retrieving the pathological results from the database, histopathological phenotypes among endoscopically diagnosed AG patients were divided into four groups-metaplasia, dysplasia, AG and inflammatory activity (Figure 1). Patient demographics categorized in different group are shown in Table 1.

Of the 349 IM patients, 23 had atrophy and 119 had dysplasia but none of

Table 1. Demographics of study population.

\begin{tabular}{|c|c|c|c|c|c|}
\hline & $\begin{array}{l}\text { Intestinal } \\
\text { Metaplasia }\end{array}$ & Dysplasia & $\begin{array}{l}\text { Atrophic } \\
\text { Gastritis }\end{array}$ & $\begin{array}{c}\text { Inflammatory } \\
\text { Activity }\end{array}$ & $\begin{array}{c}\text { Total } \\
\mathrm{N}=518\end{array}$ \\
\hline \multicolumn{6}{|l|}{ Gender } \\
\hline Male & 226 & 33 & 14 & 48 & 322 \\
\hline Female & 123 & 16 & 5 & 53 & 196 \\
\hline \multicolumn{6}{|l|}{ Age } \\
\hline$\leq 40$ & 8 & 3 & 1 & 3 & 15 \\
\hline $41-50$ & 57 & 7 & 0 & 18 & 82 \\
\hline $51-60$ & 107 & 21 & 5 & 27 & 160 \\
\hline $61-70$ & 113 & 9 & 9 & 30 & 161 \\
\hline $71-80$ & 57 & 9 & 4 & 17 & 87 \\
\hline$>80$ & 7 & 0 & 0 & 6 & 13 \\
\hline
\end{tabular}




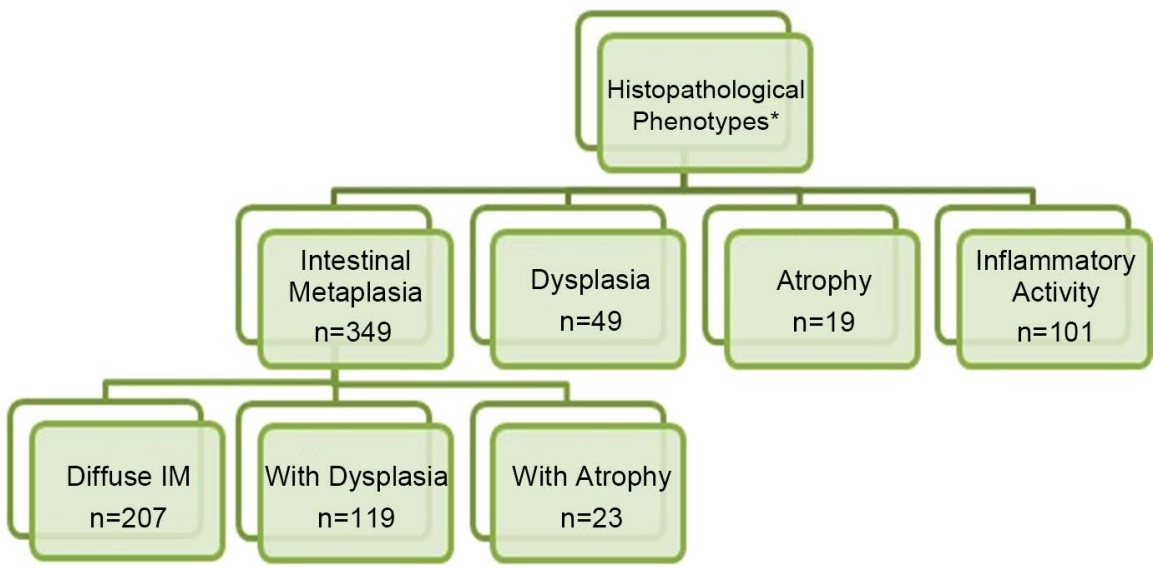

Figure 1. Classification of histopathological phenotypes among endoscopically diagnosed atrophic gastritis patients. IM: Intestinal Metaplasia; ${ }^{\star}$ Observed in 518 patients diagnosed with atrophic gastritis at endoscopy.

Table 2. Frequency of atrophy and dysplasia according to the presence and absence of intestinal metaplasia.

\begin{tabular}{ccccc}
\hline & & \multicolumn{2}{c}{ Intestinal Metaplasia } & Fisher Exact Test \\
\cline { 3 - 4 } & & $\begin{array}{c}\text { Negative } \\
\mathrm{N}=169\end{array}$ & $\begin{array}{c}\text { Positive } \\
\mathrm{N}=349\end{array}$ & P value \\
\hline \multirow{2}{*}{ Atrophy } & Positive & 19 & 23 & 0.085 \\
& Negative & 150 & 326 & \\
Dysplasia & Positive & 49 & 119 & 0.271 \\
& Negative & 120 & 230 & \\
\hline
\end{tabular}

these lesions was found to be correlated with IM $(\mathrm{P}=0.085$ and $\mathrm{P}=0.271$, respectively) (Table 2).

\subsection{Distribution of Age and Gender in Gastric Precancerous Lesions}

The most common lesion was Gastric IM observed in $67.38 \%$ of patients. Among the patients diagnosed with IM, $64.8 \%$ were male while $35.2 \%$ were female. IM increased with increase in age until 70 years (from $2.3 \%$ in those less than 40 years of age to $63.04 \%$ in those between 50 and 70) (Figure 2). Dysplasia and Atrophy were present in $9.46 \%$ and 3.67\% patients, respectively. Both lesions were common in male as compared with female. Dysplasia was most common between age 51 and 60 (42.9\%) while diffuse AG at histology was common between ages 60 and 70 (Figure 2). However, multivariate analysis did not show any significant association of male gender and increasing age with the precancerous lesions-IM, AG and dysplasia as illustrated in Table 3 and Table 4.

\subsection{Inflammatory Activity in Biopsied Samples of AG Patients}

Inflammatory (neutrophilic) activity was observed in 101 (19.49\%) subjects and 
was significantly correlated with female gender $(\mathrm{OR}=2.12 ; 95 \% \mathrm{CI}=1.36-3.28$, $\mathrm{P}=0.0008$ ). Most of these patients were between 50 and 70 years of age (56.43\%). However, in logistic regression, no significant association was found between increasing age and inflammatory activity as depicted in Table 4.

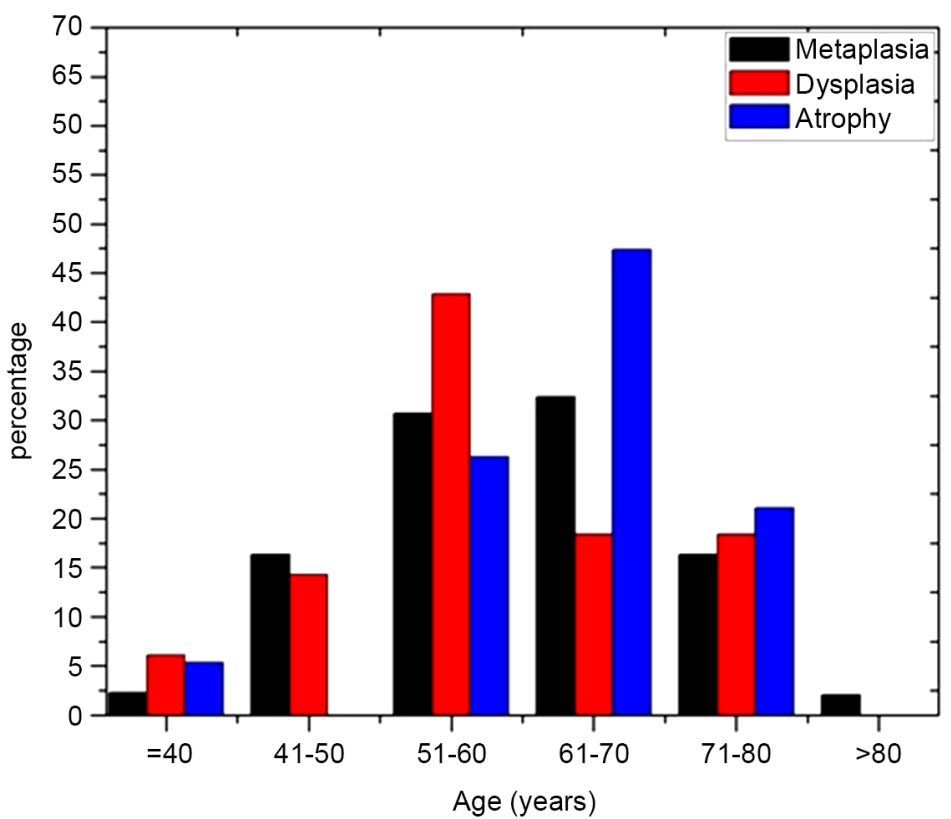

Figure 2. The percentage positivity of intestinal metaplasia, dysplasia and atrophy in 518 cases of atrophic gastritis (endoscopic) according to age group.

Table 3. Associated odds ratio for gender and age in intestinal metaplasia and dysplasia.

\begin{tabular}{|c|c|c|c|c|c|c|}
\hline \multirow{2}{*}{ Variable } & \multicolumn{3}{|c|}{ Intestinal Metaplasia } & \multicolumn{3}{|c|}{ Dysplasia } \\
\hline & Negative & Positive & OR $(95 \% \mathrm{CI})$ & Negative & Positive & OR $(95 \% \mathrm{CI})$ \\
\hline \multicolumn{7}{|l|}{ Gender } \\
\hline Male & 96 & 226 & 1 & 289 & 33 & 1 \\
\hline Female & 73 & 123 & $0.72(0.49-1.04)$ & 180 & 16 & $0.78(0.42-1.46)$ \\
\hline $\mathrm{P}$ value & & & 0.08 & & & 0.43 \\
\hline \multicolumn{7}{|l|}{ Age } \\
\hline$\leq 40$ & 7 & 8 & 1 & 12 & 3 & 1 \\
\hline $41-50$ & 25 & 57 & $1.995(0.65-6.10)$ & 75 & 7 & $0.37(0.09-1.65)$ \\
\hline $51-60$ & 53 & 107 & $1.77(0.61-5.13)$ & 139 & 21 & $0.60(0.16-2.32)$ \\
\hline $61-70$ & 48 & 113 & $2.06(0.71-6.00)$ & 152 & 9 & $0.24(0.06-0.99)$ \\
\hline $71-80$ & 30 & 57 & $1.66(0.55-5.03)$ & 78 & 9 & $0.46(0.11-1.95)$ \\
\hline$>80$ & 6 & & $1.02(0.23-4.53)$ & 13 & 0 & $0.13(0.01-2.83)$ \\
\hline$P$ value & 7 & & 0.98 & & & 0.20 \\
\hline
\end{tabular}

OR: odds ratio; $\mathrm{CI}$, confidence interval. 
Table 4. Associated odds ratio for gender and age in inflammatory activity and atrophy.

\begin{tabular}{|c|c|c|c|c|c|c|}
\hline \multirow{2}{*}{ Variable } & \multicolumn{3}{|c|}{ Intestinal Metaplasia } & \multicolumn{3}{|c|}{ Dysplasia } \\
\hline & Negative & Positive & OR (95\% CI) & Negative & Positive & OR (95\% CI) \\
\hline \multicolumn{7}{|l|}{ Gender } \\
\hline Male & 274 & 48 & 1 & 308 & 14 & 1 \\
\hline Female & 143 & 53 & $2.12(1.36-3.28)$ & 191 & 5 & $0.58(0.20-1.63)$ \\
\hline$P$ value & & & 0.0008 & & & 0.297 \\
\hline \multicolumn{7}{|l|}{ Age } \\
\hline$\leq 40$ & 12 & 3 & 1 & 14 & 1 & 1 \\
\hline $41-50$ & 64 & 18 & $1.13(0.29-4.42)$ & 82 & 0 & $0.06(0.002-1.51)$ \\
\hline $51-60$ & 133 & 27 & $0.81(0.22-3.07)$ & 155 & 5 & $0.45(0.05-4.14)$ \\
\hline $61-70$ & 131 & 30 & $0.92(0.24-3.45)$ & 152 & 9 & $0.83(0.098-7.03)$ \\
\hline $71-80$ & 70 & 17 & $0.97(0.25-3.83)$ & 83 & 4 & $0.68(0.07-6.49)$ \\
\hline$>80$ & 7 & 6 & $3.43(0.65-18.22)$ & 13 & 0 & $0.36(0.01-9.57)$ \\
\hline$P$ value & & & 0.15 & & & 0.54 \\
\hline
\end{tabular}

OR: odds ratio; CI, confidence interval.

\section{Discussion}

Gastric Cancer is usually preceded by a cascade of lesions from non-atrophic gastritis to atrophic gastritis (AG), intestinal metaplasia (IM), dysplasia and finally carcinoma [9]. Helicobacter Pylori is the most common causative agent for the development of this cascade and therefore, the bacterium is classified as a Class I carcinogen by the International Agency for Research on Cancer of the World Health Organization [10]. Atrophic Gastritis and Gastric IM are well established as premalignant lesions in the literature [11] [12] [13] [14]. Atrophic gastritis is characterized by loss of normal architecture of gastric mucosa while in intestinal metaplasia, the normal gastric glands are replaced by glands that morphologically and histologically resemble those, found in the intestine.

IM is much more prevalent in East Asia, as compared with rest of the world. In our study, gastric IM was the most common lesion (67.38\%) observed in the biopsies retrieved from endoscopically diagnosed AG patients. This high frequency of IM was consistent with a recent published retrospective study from South China [15]. Chen et al. [15] inducted 3969 patients endoscopically diagnosed with AG. One or two biopsies were taken from the antrum of all subjects. IM was present in $84.33 \%$ of these patients with IM correlating significantly with the severity of AG. In Korea, prevalence of gastric intestinal metaplasia was found to be $42.5 \%$ and $32.7 \%$ in antrum and corpus, respectively [16].

In a large multicenter study from Japan [17], prevalence of atrophic gastritis and IM was much higher in $H$. pylori infected patients compared with uninfected 
patients $(\mathrm{OR}=44.8 ; 95 \% \mathrm{CI}=34.7-57.8$ and $\mathrm{OR}=11.5 ; 95 \% \mathrm{CI}=8.5-15.5$, respectively). In a study from Nigeria [18], gastric intestinal metaplasia was the most common lesion observed in gastro duodenal biopsies followed by AG and dysplasia. Eighty percent of the study population was positive for $H$. pylori, thus signifying a strong association between $H$. pylori and IM in agreement with the aforementioned study from Japan. In contrast, low prevalence of $H$. pylori in atrophic mucosa have been reported in the literature [19] [20]. Our study was confined to only patients with atrophy at endoscopy and biopsy samples retrieved from study subjects were not assessed for $H$. pylori presuming for low prevalence of $H$. pylori in atrophic gastritis.

A study from USA [21] reported that prevalence of gastric intestinal metaplasia was $15 \%$ among the 437 patients who had gastric biopsies performed. Olmez et al. [22] reported that, among the 4050 patients who had gastric biopsies performed, 560 were found to have gastric IM and they observed that the overall prevalence was $13.8 \%$ with IM Type III being the most prevalent among the IM subjects. A study from Romania [23] reported that the frequency of intestinal metaplasia was $61.6 \%$ in patients suffering from chronic gastritis, most of the cases presented with complete type IM.

At our institution, IM subtyping is not routinely practiced and extension of metaplastic change is generally observed in gastric mucosal samples. Conflicting data is found in the literature for subtyping IM and therefore, it is not widely practiced. Some authors describe a positive effect of typing IM and concluded that IM Type III carries the highest risk for developing gastric cancer whilst others refute it [24] [25] [26] [27]. On the other hand, extension of atrophic and metaplastic lesions is well accepted as a determinant for neoplastic changes and various guidelines exist to evaluate the extension of atrophy and/or IM [14] [28] [29]. The European Society of Gastrointestinal Endoscopy and other European academic societies, recommended guidelines to assess extent of atrophy and/or IM rather IM subtyping as an indicator for the surveillance of patients with atrophic gastritis and/or IM [30].

Increasing age and male gender have been reported to be significantly related to development of intestinal metaplasia [16] [31] [32]. On the other hand, IM was predominant in female gender as compared with male and the difference was statistically significant in a study reported from USA [19]. In our study, IM was more common in males than females but the difference was not statistically significant $(\mathrm{OR}=0.72 ; \mathrm{CI}=0.49-1.04 ; \mathrm{P}>0.05)$. In addition, increasing age was NOT found to be a risk factor for the development of IM $(P=0.98)$. The contradictory results may be attributed to geographical variations and difference in the size of study population.

Fragments from mucosa of 101 patients showed inflammatory (neutrophilic) activity under microscope. Interestingly, it was significantly related with female gender but not with age.

We could not evaluate $H$. pylori status in the study population. However, the bacterium is highly prevalent in China [33] and we assume that the inflammatory 
activity will most likely be due to presence of $H$. pylori that has the tendency to lead to neutrophilic activation and chronic gastritis [34].

The limitations of this study are as follows: first, study population was not large enough to give a better picture of the frequency of histopathological phenotypes among AG subjects. Secondly, in this study, H. pylori status for all the inducted patients could not be retrieved. Third, we only evaluated age and gender for extensive IM while other risk factors-such as alcohol consumption, smoking, increased BMI and high salt intake-are also known to contribute in the development of gastric precancerous lesions and gastric cancer.

\section{Conclusion}

In conclusion, our results show that histopathological diagnosis carries a pivotal role in patients with endoscopic diagnosis of AG. Our study highlighted the various histopathological phenotypes among AG patients with "gastric IM" being the most common lesion. More prospective cohort studies may be designed to: 1) determine the prevalence of gastric precancerous lesions in the general population in the North-East region; 2) evaluate relative risk of each individual phenotype to advance into a neoplasm which may aid in formulating surveillance guidelines for each phenotype; 3 ) identify the risk factors associated with the development of the precancerous lesions; and 4) determine the prevalence of $H$. pylori in the precancerous lesions in our region.

\section{References}

[1] Bertuccio, P., Chatenoud, L., Levi, F., et al. (2009) Recent Patterns in Gastric Cancer: A Global Overview. International Journal of Cancer, 125, 666-673.

https://doi.org/10.1002/ijc.24290

[2] Yang, L. (2006) Incidence and Mortality of Gastric Cancer in China. World Journal of Gastroenterology, 12, 17-20. https://doi.org/10.3748/wjg.v12.i1.17

[3] Jemal, A., Bray, F., Center, M.M., Ferlay, J., Ward, E. and Forman, D. (2011) Global Cancer Statistics. CA: A Cancer Journal of Clinicians, 61, 69-90. https://doi.org/10.3322/caac.20107

[4] Yoon, H. and Kim, N. (2015) Diagnosis and Management of High Risk Group for Gastric Cancer. Gut and Liver, 9, 5-17. https://doi.org/10.5009/gnl14118

[5] Correa, P. (1988) Chronic Gastritis: A Clinico-Pathological Classification. American Journal of Gastroenterology, 83, 504-509.

[6] Marques-Silva, L., Areia, M., Elvas, L. and Dinis-Ribeiro, M. (2014) Prevalence of Gastric Precancerous Conditions: A Systematic Review and Meta-Analysis. European Journal of Gastroenterology and Hepatology, 26, 378-387. https://doi.org/10.1097/MEG.0000000000000065

[7] Melanie, M.W. and Hermann, B. (2006) Prevalence of Chronic Atrophic Gastritis in Different Parts of the World. Cancer Epidemiology, Biomarkers and Prevention, 15, 1083-1094. https://doi.org/10.1158/1055-9965.EPI-05-0931

[8] Kato, I., Tominaga, S., Ito, Y., et al. (1992) A Prospective Study of Atrophic Gastritis and Stomach Cancer Risk. Cancer Science, 83, 1137-1142. https://doi.org/10.1111/j.1349-7006.1992.tb02736.x

[9] Correa, P. (1992) Human Gastric Carcinogenesis: A Multistep and Multifactorial 
Process-First American Cancer Society Award Lecture on Cancer Epidemiology and Prevention. Cancer Research, 52, 6735-6740.

[10] No Authors (1994) Infection with Helicobacter Pylori. IARC Monographs on the Evaluation of Carcinogenic Risks to Humans, 61, 177-240.

[11] Sipponen, P., Kekki, M., Haapakoski, J., Ihamaki, T. and Siurala, M. (1985) Gastric Cancer Risk in Chronic Atrophic Gastritis: Statistical Calculations of Cross-Sectional Data. International Journal of Cancer, 35, 173-177. https://doi.org/10.1002/ijc.2910350206

[12] Uemura, N., Okamoto, S., Yamamoto, S., Matsumura, N., Yamaguchi, S., Yamakido, M., Taniyama, K., Sasaki, N. and Schlemper, R.J. (2001) Helicobacter pylori Infection and the Development of Gastric Cancer. New England Journal of Medicine, 345, 784-789. https://doi.org/10.1056/NEJMoa001999

[13] De Vries, A.C., van Grieken, N.C.T., Looman, C.W.N., et al. (2008) Gastric Cancer Risk in Patients with Premalignant Gastric Lesions: A Nationwide Cohort Study in the Netherlands. Gastroenterology, 134, 945-952. https://doi.org/10.1053/j.gastro.2008.01.071

[14] Zullo, A., Hassan, C., Romiti, A., Giusto, M., Guerriero, C., Lorenzetti, R., Campo, S.M. and Tomao, S. (2012) Follow-Up of Intestinal Metaplasia in the Stomach: When, How and Why. World Journal of Gastrointestinal Oncology, 4, 30-36. https://doi.org/10.4251/wjgo.v4.i3.30

[15] Chen, S., Ying, L., Kong, M., Zhang, Y. and Li, Y. (2013) The Prevalence of Helicobacter pylori Infection Decreases with Older Age in Atrophic Gastritis. Gastroenterology Research and Practice, 2013, Article ID: 494783. https://doi.org/10.1155/2013/494783

[16] Kim, H.J., Choi, B.Y., Byun, T.J., Eun, C.S., Song, K.S., Kim, Y.S., et al. (2008) The Prevalence of Atrophic Gastritis and Intestinal Metaplasia According to Gender, Age and Helicobacter pylori Infection in a Rural Population. Journal of Preventive Medicine \& Public Health, 41, 373-379. https://doi.org/10.3961/jpmph.2008.41.6.373

[17] Asaka, M., Sugiyama, T., Nobuta, A., Kato, M., Takeda, H. and Graham, D.Y. (2001) Atrophic Gastritis and Intestinal Metaplasia in Japan: Results of a Large Multicenter Study. Helicobacter, 6, 294-299. https://doi.org/10.1046/j.1523-5378.2001.00042.x

[18] Badmos, K.B., Ojo, O.S., Olasode, B.J. and Arigbabu, A.O. (2012) Gastric Precancerous lesions among Nigerians with Chronic Gastritis. Nigerian Postgraduate Medical Journal, 19, 92-96.

[19] Siurala, M., Sipponen, P. and Kekki, M. (1988) Campylobacter pylori in a Sample of Finnish Population: Relations to Morphology and Functional Aspects of Gastric Mucosa. Gut, 29, 909-916. https://doi.org/10.1136/gut.29.7.909

[20] Muller, L.B., Fagundes, R.B., Moraes, C.C. and Rampazzo, A. (2007) Prevalence of Helicobacter pylori Infection and Gastric Cancer Precursor Lesions in Patients with Dyspepsia. Archives of Gastroenterology, 44, 93-98.

[21] Almouradi, T., Hiatt, T. and Attar, B. (2013) Gastric Intestinal Metaplasia in an Underserved Population in the USA: Prevalence, Epidemiologic and Clinical Features. Gastroenterology Research and Practice, 2013, Article ID: 856256. https://doi.org/10.1155/2013/856256

[22] Olmez, S., Aslan, M., Erten, R., Sayar, S. and Bayram, I. (2015) The Prevalence of Gastric Intestinal Metaplasia and Distribution of Helicobacter pylori Infection, Atrophy, Dysplasia, and Cancer in Its Subtypes. Gastroenterology Research and Practice, 2015, Article ID: 434039. https://doi.org/10.1155/2015/434039 
[23] Dîrnu, R., et al. (2012) Chronic Gastritis with Intestinal Metaplasia: Clinico-Statistical, Histological and Immunohistochemical Study. Romanian Journal of Morphology and Embryology, 53, 293-297.

[24] Filipe, M.I., Munoz, N., Matko, I., et al. (1994) Intestinal Metaplasia Type and the Risk of Gastric Cancer: A Cohort Study in Slovenia. International Journal of Cancer, 57, 324-329. https://doi.org/10.1002/ijc.2910570306

[25] Rokkas, T., Filipe, M.I. and Sladen, G.E. (1991) Detection of an Increased Incidence of Early Gastric Cancer in Patients with Intestinal Metaplasia Type III Who Are Closely Followed up. Gut, 32, 1110-1113. https://doi.org/10.1136/gut.32.10.1110

[26] El-Zimaity, H.M.T., Ramchatesingh, J., Ali Saeed, M. and Graham, D.Y. (2001) Gastric Intestinal Metaplasia: Subtypes and Natural History. Journal of Clinical Pathology, 54, 679-683. https://doi.org/10.1136/jcp.54.9.679

[27] Kang, K.P., Lee, H.S., Kim, N., et al. (2009) Role of Intestinal Metaplasia Subtyping in the Risk of Gastric Cancer in Korea. Journal of Gastroenterology and Hepatolo$g y, 24,140-148$. https://doi.org/10.1111/j.1440-1746.2008.05546.x

[28] Rugge, M., de Boni, M., Pennelli, G., et al. (2010) Gastritis OLGA-Staging and Gastric Cancer Risk: A Twelve-Year Clinico-Pathological Follow-Up Study. Alimentary Pharmacology \& Therapeutics, 31, 1104-1111.

[29] Capelle, L.G., de Vries, A.C., Haringsma, J., et al. (2010) The Staging of Gastritis with the OLGA System by Using Intestinal Metaplasia as an Accurate Alternative for Atrophic Gastritis. Gastrointestinal Endoscopy, 71, 1150-1158.

https://doi.org/10.1016/j.gie.2009.12.029

[30] Dinis-Ribeiro, M., Areia, M., de Vries, A.C., et al. (2012) Management of Precancerous Conditions and Lesions in the Stomach (MAPS): Guideline from the European Society of Gastrointestinal Endoscopy (ESGE), European Helicobacter Study Group (EHSG), European Society of Pathology (ESP), and the Sociedade Portuguesa de EndoscopiaDigestiva (SPED). Endoscopy, 44, 74-94. https://doi.org/10.1055/s-0031-1291491

[31] Joo, Y., Park, H., Myung, D., Baik, G., Shin, J., Seo, G., Kim, G., Kim, H., Kim, H., Cho, S. and Kim, N. (2013) Prevalence and Risk Factors of Atrophic Gastritis and Intestinal Metaplasia: A Nationwide Multicenter Prospective Study in Korea. Gut and Liver, 7, 303-310. https://doi.org/10.5009/gnl.2013.7.3.303

[32] Cazacu, S.M., Vere, C.C., Bodrug, N., et al. (2009) The Influence of Risk Factors to the Prevalence of Gastric Mucosal Atrophy, Intestinal Metaplasia and Dysplasia in Oltenia Region. Current Health Sciences Journal, 35, 13-15.

[33] Shi, R., Xu, S., Zhang, H., et al. (2008) Prevalence and Risk Factors for Helicobacter pylori Infection in Chinese Populations. Helicobacter, 13, 157-165.

https://doi.org/10.1111/j.1523-5378.2008.00586.x

[34] Tanko, M.N., Manasseh, A.N., Echejoh, G.O., et al. (2008) Relation between Helicobacter pylori, Inflammatory (Neutrophil) Activity, Chronic Gastritis, Gastric Atrophy and Intestinal Metaplasia. Nigerian Journal of Clinical Practice, 11, 270-274. 
Submit or recommend next manuscript to SCIRP and we will provide best service for you:

Accepting pre-submission inquiries through Email, Facebook, LinkedIn, Twitter, etc. A wide selection of journals (inclusive of 9 subjects, more than 200 journals)

Providing 24-hour high-quality service

User-friendly online submission system

Fair and swift peer-review system

Efficient typesetting and proofreading procedure

Display of the result of downloads and visits, as well as the number of cited articles Maximum dissemination of your research work

Submit your manuscript at: http://papersubmission.scirp.org/

Or contact ojgas@scirp.org 